\title{
El imperialismo y el culturalismo se complementan mutuamente
}

\author{
SAMIR AMIN*
}

\section{RESUMEN}

El capitalismo siempre está preparado para premiar a aquellos académicos y publicistas que aporten explicaciones plausibles y exculpatorias para sus crisis, fallos y crímenes. Frecuentemente, las explicaciones más efectivas son aquellas que se aprovechan de los prejuicios y supersticiones previas al desarrollo de la ciencia (o "premodernas"), pero que se presentan como modernas y científicas. Las alternativas preferidas al materialismo histórico han sido las teorías sobre la evolución histórica del mundo producido por el desarrollo de "civilizaciones" o "culturas", cerradas y separadas las unas de las otras. Estas "civilizaciones" y "culturas" no se explican por la historia, sino que explican la historia. Una de las versiones actuales de estas teorías es la del publicista (y Profesor de Harvard) Samuel Huntington, justificando los crímenes del imperialismo como producto de la "incompatibilidad" cultural. Esta es simplemente la "versión más autorizada" de un ruido que actualmente puede escucharse en todos ritmos, melodías y disonancias, a menudo con sus orígenes en una ligeramente disfrazada pseudociencia racial. Otras versiones, suavizadas e incompletas, se presentan a veces como "políticas identitarias" o "comunitarismo". El periódico egipcio Al Ahram ha preguntado a nuestro buen amigo y colaborador frecuente Samir Amin para darnos su opinión sobre la teoría del "choque de civilizaciones" de Huntington. Su demostración de por qué el culturalismo y el imperialismo se fortalecen mutuamente, y cómo las víctimas pueden ser llevadas a aceptar la "diferencia" en lugar de igualdad y liberación, es hoy de utilidad potencial en cualquier lugar del mundo.

\section{Palabras clave}

Culturalismo; Imperialismo; Choque de Civilizaciones.

\section{TITLE}

Imperialism and culturalism complement each other

\section{Abstract}

Capitalism is always ready to reward academics and publicists who provide plausible exculpatory explanations for its crises, failures, and crimes. Frequently the most effective are those that play upon the prejudices and superstitions of the prescientific past but in modern (or "post-modern") and scientific farm. Favored alternatives to historical materialist social science have been theories of world-historical process as the working out of closed and separate "civilizations" or "cultures." These "civilizations" and "cultures" are not explained by history, but instead explain history. One current version is that of the publicist (and Harvard Professor) Samuel Huntington, justifying the crimes of imperialism as the product of cultural "incompatibility." This is merely the most Authorized Version of a noise that can be heard today in all rhythms, tunes, and dissonances, often with its origins in racial pseudo-science only slightly disguised. Other varyingly sanitized and fragmentary versions are sometimes presented as "identity politics" or "communitarianism." The Egyptian journal Al Ahram asked our good friend and frequent contributor Samir Amin to give his view of Huntington's theory of "clash of civilizations." His demonstration of why culturalism and imperialism reinforce each other, and how victims can be led to accept "difference" in place of equality and liberation, is today of potential utility everywhere.

\section{KEYWORDS}

Culturalism; Imperialism; Clash of Civilizations.

\section{DOI:}

https://doi.org//0.15366/relacionesinternacionales2019.42.00।

Formato de citación recomendado:

AMIN, Samir, "El imperialismo y el culturalismo se complementan mutuamente”, en Relaciones Internacionales, $n^{\circ} 42,2019$, pp. 13-20. 
I capitalismo siempre está preparado para premiar a aquellos académicos y publicistas que aporten explicaciones plausibles y exculpatorias para sus crisis, fallos y crímenes. Frecuentemente, las explicaciones más efectivas son aquellas que se aprovechan de los prejuicios y supersticiones previas al desarrollo de la ciencia (o "premodernas"), pero que se presentan como modernas y científicas. Las alternativas preferidas al materialismo histórico han sido las teorías sobre la evolución histórica del mundo producido por el desarrollo de "civilizaciones" o "culturas", cerradas y separadas las unas de las otras. Estas "civilizaciones" y "culturas" no se explican por la historia, sino que explican la historia. Una de las versiones actuales de estas teorías es la del publicista (y Profesor de Harvard) Samuel Huntington, justificando los crímenes del imperialismo como producto de la "incompatibilidad" cultural. Esta es simplemente la "versión más autorizada" de un ruido que actualmente puede escucharse en todos ritmos, melodías y disonancias, a menudo con sus orígenes en una ligeramente disfrazada pseudociencia racial. Otras versiones, suavizadas e incompletas, se presentan a veces como "políticas identitarias" o "comunitarismo". El periódico egipcio Al Ahram ha preguntado a nuestro buen amigo y colaborador frecuente Samir Amin para darnos su opinión sobre la teoría del "choque de civilizaciones" de Huntington. Su demostración de por qué el culturalismo y el imperialismo se fortalecen mutuamente, y cómo las víctimas pueden ser llevadas a aceptar la "diferencia" en lugar de igualdad y liberación, es hoy de utilidad potencial en cualquier lugar del mundo. - Los editores.

Las ideologías dominantes son, por definición, conservadoras: con el fin de reproducirse, todas las formas de organización social deben percibirse como el fin de la historia. Sin embargo, el primer paso del pensamiento científico consiste precisamente en tratar de ir más allá de la visión que los propios sistemas sociales tienen de sí mismos. El discurso dominante conservador adquiere fuerza a través de la práctica vulgar de mezclar entre sí los "valores" con los que se pretende gobernar el mundo moderno. A este saco se lanzan los principios de organización política (conceptos de legalidad, del estado, derechos humanos, democracia), valores sociales (libertad, igualdad, individualismo) y los principios de organización de la vida económica (propiedad privada, el "libre mercado"). Esta amalgama lleva la falsa declaración de que todos estos conceptos constituyen un todo indivisible, surgidos de un mismo proceso lógico. De ahí la asociación del capitalismo con la democracia, como si este fuese un vínculo obvio o necesario. Sin embargo, la historia muestra lo contrario: los avances democráticos se han ganado a través de la lucha, no son productos naturales ni espontáneos de la expansión capitalista.

I

A menos que queramos que "el fin de la historia" implique el fin de la historia de la humanidad y del planeta a través de su destrucción, el capitalismo debe ser superado. Al contrario que sistemas anteriores, los cuales se desarrollaron durante miles de años antes de que se agotara su potencial histórico, el capitalismo puede aparecer como un breve paréntesis en la historia.Aunque actualmente las tareas de acumulación se han conseguido, estas solo llevan al pavimento del camino a un orden social sustituto, caracterizado por una racionalidad superior, no alienada y basada en un auténtico humanismo universal. En otras palabras, el capitalismo ha agotado su potencial histórico positivo hace tiempo; ha dejado de ser el medio (aunque solo sea el "inconsciente") por el cual el progreso encuentra su camino, y ahora se ha convertido en un obstáculo para progresar.

El progreso no se identifica aquí como un producto abstracto e involuntario conectado 
a la expansión del capital, sino que se define independientemente a través de criterios humanos endebles frente a los productos reales del capitalismo, que son la alienación económica, la destrucción ecológica y la polarización global. Esta contradicción explica porqué la historia del capitalismo ha sido construida desde sus orígenes por sucesivos movimientos opuestos. Mientras que en unos periodos la lógica de la expansión del capital se experimenta como una fuerza unilateral, en otros la intervención de fuerzas antisistema limita la extensión de la destrucción inherente a su expansión.

En el siglo XIX, el desarrollo desigual de la Revolución Industrial, la proletarización y la colonización son las características de la primera forma de expansión capitalista. Pero a pesar de los himnos de gloria del capital, la violencia de las contradicciones del capitalismo no ha conducido al fin de la historia, como se anunciaba en términos triunfalistas de la "belle epoque", sino a guerras mundiales, revoluciones socialistas y la revuelta de los pueblos colonizados. Reestablecido en la Europa de la post Primera Guerra Mundial, el liberalismo triunfal agravó el caos y sembró el camino a la respuesta criminal e ilusoria que el fascismo proporcionaría.

Por tanto, es solo desde 1945 y en adelante, tras el fracaso del fascismo, cuando se abriría una nueva fase de expansión civilizada a través de los compromisos históricos impuestos por el sovietismo, la socialdemocracia y los movimientos de liberación nacional. Ninguno de estos compromisos rompió completamente con la lógica del capitalismo, pero todos ellos impusieron al capital el respeto por los movimientos resultantes de la explosión de las contradicciones del capitalismo. En su desarrollo, estos compromisos moderaron en la práctica los efectos devastadores de la alienación económica y la polarización. Pero esta fase ha finalizado. Degradados progresivamente por sus éxitos, parciales por definición, esta lógica de compromiso cayó con el colapso de los sistemas que había legitimado. Uno solo puede preguntar: ¿es el actual regreso al discurso del triunfal liberalismo, que cree de nuevo en el fin de la historia, solo el anuncio de una trágica repetición de las dramáticas escenas anteriores? ¿No ha creado este neoliberalismo en tiempo récord un vacío ideológico, y a su vez traído las condiciones para reforzar la polarización?

Desde luego, las víctimas de este sistema reaccionarían. Ya están reaccionando. ¿Pero qué lógica desarrollarán en oposición a la lógica del capital? ¿Qué tipo de compromisos impondrán sobre él? En la hipótesis más radical, ¿qué sistemas sustituirían al capitalismo? Las estrategias en torno a las que giraban las movilizaciones sociales que tuvieron lugar en el periodo anterior (socialismo y construcción de estados-nación) han perdido hoy su credibilidad como resultado de la falta de renovación en su respuesta a los nuevos elementos surgidos de los retos del capitalismo. Uno puede ver ya qué sistemas han aparecido como sustitutos: la democracia (siempre limitada implícitamente por algún grupo privilegiado) asociada con formas de comunalismo (generalmente étnico), cuyo reconocimiento está legitimado por el "derecho de diferencia" y a veces por el ecologismo; o la singularidad cultural, y especialmente religiosa.

\section{II}

La idea de que las diferencias culturales no son solo reales e importantes, sino fundamentales, permanentes y estables, lo que viene a decir que son transhistóricas, no es una idea nueva. Al contrario, es la base de los prejuicios de todos los pueblos en todos los periodos históricos. Todas las religiones se definen a sí mismas de esta forma, como el fin de la historia, como la respuesta 
definitiva. Pero el progreso en la reflexión crítica, social e histórica (un avance universal), y la construcción de las ciencias sociales siempre han requerido de una lucha continua contra el prejuicio y la inmutabilidad cultural. Las culturas y religiones están continuamente cambiando, y este cambio se puede explicar. Por tanto, la cuestión no es demostrar una vez más que esta forma de ver el mundo se contradice por la historia real. Lo primero es saber por qué la absurda idea de "culturas" entendidas fuera de la historia se presenta actualmente con tanta fuerza y convicción, y posteriormente entender los resultados de su éxito político.

Las teorías sobre la especificidad cultural son en general frustrantes, ya que se basan en el prejuicio de que las diferencias son siempre decisivas mientras que las similitudes son producto de meras coincidencias. Los resultados deseados por dicho proyecto son obtenidos, a priori, por esta tesis. Pero las diferencias que se alegan delatan la banalidad implicada en esta reflexión. Decir, como hace Samuel Huntington en su famoso artículo "el Choque de Civilizaciones", que estas diferencias son fundamentales al involucrar ámbitos que definen "las relaciones entre los seres humanos y Dios, la Naturaleza, el Poder", es reducir las culturas a las religiones y al mismo tiempo suponer que cada cultura desarrolla conceptos específicos e inalterables respecto a las relaciones categóricas predeterminadas por Huntington.

Pero la historia muestra que estos conceptos son más flexibles de lo que a menudo se cree. Y que se encuentran en sistemas ideológicos inscritos en diversas formas de evolución histórica de acuerdo a circunstancias independientes de los conceptos en sí mismos. Los malos culturalistas - iacaso los hay buenos? - explicaban ayer el atraso de China como lo hacen hoy con su acelerado desarrollo, en el mismo confucianismo. Para muchos historiadores, el mundo islámico del siglo $X$ no solo parecía más brillante, sino también con más potencial para el progreso que la Europa cristiana del mismo periodo. Entonces, ¿qué ha cambiado para explicar la inversión posterior de estas posiciones? ¿La religión (más precisamente su interpretación por la sociedad), alguna otra cuestión, o ambas cosas? ¿Y cómo estos diferentes ejemplos de realidad reaccionan entre sí? ¿Cuál es la fuerza motriz? Estas son las preguntas a las cuales el culturalismo, incluso en formulaciones más rigurosas que la de Huntington, cuya versión es particularmente tosca, es indiferente.

Es más, ¿de qué culturas estamos hablando? ¿Aquellas definidas por un espacio religioso, por el lenguaje, por "nación”, por regiones económicamente homogéneas o por sistemas políticos? Aparentemente, Huntington ha elegido la "religión" como la base de sus "siete grupos", entre los que diferencia el Occidental (católicos y protestantes), el Musulmán', el Confucionista (jaunque el confucionismo no es una religión!), el Japonés (¿sintoístas o confucionistas?), Hindú, Budista y el Cristiano Ortodoxo. Huntington está claramente interesado en los espacios culturales que potencialmente explicarían las importantes divisiones que existen en el mundo actual. No hay duda, por ejemplo, sobre por qué necesitaba separar a los japoneses de otros confucionistas y ortodoxos cristianos de los Occidentales (ies porque en la estrategia del Departamento de Estado, en la cual Huntington está abiertamente interesado, la potencial integración de Rusia en Europa sigue considerándose una auténtica pesadilla?). Tampoco hay mucha duda sobre por qué ignora a los africanos, quienes, aunque sean cristianos, musulmanes o animistas, mantienen Nota de traducción: en el artículo El Choque de Civilizaciones de Samuel Huntington, éste utiliza el término de "civilización islámica", mientras
que Samir Amin utiliza el término "grupo musulmán". 
una serie de particularidades propias (aunque esta omisión de Huntington tal vez solo refleje ignorancia y un banal prejuicio racial), e incluso los latinoamericanos iporqué si son cristianos no son tan "occidentales" como los occidentales? Y, si lo fuesen ¿por qué están subdesarrollados? No sería difícil señalar las demás ridiculeces de esta mal escrita página de eurocentrismo de poca monta.

Huntington realiza esta elaborada taxonomía para llegar al increíble descubrimiento de que seis de los siete grupos ignoran completamente los valores occidentales, entre los que encontramos la asociación, mediante juego de manos, característica de este género: conceptos definiendo el capitalismo ("el mercado") y la democracia (asociada al capitalismo por decreto, a pesar de los hechos históricos). ¿Pero es el coste del mercado peor en el Japón no occidental que en América Latina? ¿No son el mercado y la democracia fenómenos recientes en el propio Occidente? ¿Se reconoció a si misma la cristiandad medieval en estos supuestos valores "occidentales" transhistóricos?

Las ideologías -especialmente las religiosas - son sin duda importantes. Pero durante doscientos años hemos estado desarrollando análisis que sitúan a la ideología dentro de la sociedad, y podemos identificar analogías útiles en diferentes sociedades sujetas a condiciones históricas similares. Dichas analogías entre las funciones sociales de las ideologías religiosas pueden ser claramente vistas por encima de sus particularidades. En este marco, diversos "espacios religiosos" tradicionales no han desaparecido, y están lejos de ello. Pero éstas se han transformado profundamente desde su interior, y sin el capitalismo moderno (al cual Huntington llama, erróneamente, "cultura occidental"). Yo he llegado a la conclusión de que esta cultura del capitalismo (y no la de "Occidente") era la globalmente dominante, y fue esta dominación la que vació de su contenido a culturas antiguas. Donde el capitalismo está más desarrollado, su cultura moderna ha sustituido internamente a culturas antiguas, como la cristiandad medieval en Europa y América del Norte, lo que ocurrió paralelamente con el confucionismo de Japón. Por otro lado, en las periferias capitalistas la cultura capitalista dominante no tuvo la capacidad de transformar radicalmente las antiguas culturas locales. Esta diferencia no tiene nada que ver con el carácter específico de la diversidad cultural tradicional, sino con las formas de expansión capitalista, tanto en los centros como en las periferias.

En su expansión global, el capitalismo ha dejado ver la contradicción entre las pretensiones universalistas y las polarizaciones que producen en la realidad material.Vacíos de todo contenido, los valores invocados por el capitalismo en nombre del universalismo (individualismo, democracia, libertad, igualdad, secularismo, el gobierno de la ley, etc.) aparecen como mentiras para las víctimas de este sistema, o como valores únicamente apropiados para la "cultura occidental". Esta contradicción es obviamente permanente, y en cada fase de profundización de la globalización (incluyendo la que estamos atravesando) se extiende su violencia. Es entonces cuando el sistema descubre, gracias al pragmatismo que lo caracteriza, el significado de gestionar la contradicción. Le basta con que cada uno acepte la "diferencia", que el oprimido deje de demandar democracia, libertad individual e igualdad con el fin de sustituir esto por los valores "apropiados", que normalmente son justo lo contrario. En este útil modelo, las víctimas internalizan su status de subalternos, permitiendo al capitalismo desarrollarse sin encontrar ningún obstáculo serio a la polarización que necesariamente provoca su expansión. 
Por tanto, el imperialismo y el culturalismo son siempre buenos compañeros. El primero se expresa mediante la arrogante certidumbre de que "Occidente" ha llegado al final de la historia, que la fórmula de gestionar la economía (propiedad privada, el mercado), la vida política (democracia), la sociedad (libertad individual), se basa en que las mismas están interconectadas a priori, son definitivas e insuperables. Las condiciones reales que se pueden observar se declaran como imaginarias, o se declaran producto de una absurda resistencia a la sumisión de la racionalidad capitalista. Para todos los demás pueblos, la elección es simple: aceptar esta falsa unidad de los "valores occidentales" o encerrarse en torno a sus particularidades culturales. Dada la polarización que el "mercado" y el imperialismo producen, si la primera de estas dos opciones resulta imposible (como lo es el caso de la mayoría del mundo), entonces el conflicto cultural ocupará el primer plano. Sin embargo, en este conflicto los dados están siempre echados: "Occidente" siempre ganará, y los demás serán siempre vencidos. Este es el motivo por el que otras opciones culturalistas no solo deben ser toleradas, sino que incluso deben incentivarse, porque estas solo suponen una amenaza para las víctimas. Dada esta situación, y al contrario del discurso mitológico del "fin de la historia" y el "choque de civilizaciones", el análisis crítico busca definir los verdaderos intereses y retos a los que nos enfrentamos. Lleno de contradicciones que no pueden trascender su propia lógica, el capitalismo es solo un paso en la historia, los valores que proclama se presentan sin su correspondiente contextualización histórica, con los límites y contradicciones del propio capitalismo, y por ende se encuentran vacíos.

El discurso autocomplaciente de "Occidente" no responde a estos retos, dado que los ignora deliberadamente. Pero el discurso culturalista de las víctimas los evita igualmente, dado que traslada el conflicto fuera del ámbito de los intereses que realmente están en juego - aquellos que da al enemigo - para encontrar refugio en el espacio imaginario de la cultura. ¿Qué importa, entonces, si por ejemplo el islam está firmemente asentado en el gobierno de una sociedad local, si dentro de la jerarquía de la economía mundial las reglas del sistema encierran a las sociedades islámicas en el status de comprador en el bazar? Como el fascismo ayer, hoy el culturalismo funciona a través de mentiras: es de hecho una forma de gestionar las crisis, a pesar de sus pretensiones por ser su solución. Pero mirar hacia el futuro, y no al pasado, significa preguntarse cuestiones reales y enfrentarlas: ¿cómo vamos a combatir la alienación económica, el despilfarro, la polarización global; y cómo vamos a crear las condiciones que permitan el avance genuino de valores universales más allá de su formulación por el capitalismo histórico?

Simultáneamente, es necesaria la crítica sobre la herencia cultural. La modernización de Europa habría sido impensable sin la crítica a la que los europeos sometieron su propio pasado y su religión. ¿Habría empezado la modernización de China sin la crítica de su pasado, y especialmente de la ideología del confucianismo, a la que el propio maoísmo era fiel? Más tarde, la herencia (cristiana en un caso, confucianismo en el otro), sería reintegrada en la nueva cultura, pero únicamente después de haber sido radicalmente transformada por la crítica revolucionaria del pasado. Por otro lado, en el mundo islámico, el terco rechazo a participar en ninguna crítica del pasado viene acompañado (no por coincidencia) de la continua degradación de los países que se incluyen dentro de este espacio cultural en la jerarquía del orden mundial.

\section{III}

Después de haber analizado la situación, generalmente uno tiende a reflexionar sobre las 
posibilidades de desarrollo futuro. La erosión gradual de los compromisos sobre los que la expansión capitalista de la postguerra se ha desarrollado, ha abierto una nueva fase en la cual el capital, liberado de toda restricción, ha intentado imponer una utopía sobre la gestión mundial de acuerdo a la lógica unilateral de sus intereses financieros. Esta conclusión lleva a la identificación de los nuevos objetivos de la estrategia de los poderes dominantes: profundizar la globalización económica y destruir la capacidad política de resistencia.

Gestionar el mundo como un mercado implica la máxima fragmentación de las fuerzas políticas o, en otras palabras, la práctica destrucción de las fuerzas estatales (un objetivo que la ideología antiestatal intenta legitimar) en favor de "comunidades" (étnicas, religiosas, u otras), y en favor de formas primitivas de solidaridad ideológica como los fundamentalismos religiosos. Para el proyecto de gestión global, con Estados Unidos convertido en la única policía mundial, lo ideal sería que ningún otro estado ( $y$ especialmente no una potencia militarmente independiente) que mereciese tener dicha categoría pudiese sobrevivir. Todos los demás poderes estarían limitados a las modestas tareas de la gestión diaria del mercado. El proyecto europeo se concibe en los términos de gestión comunitaria del mercado y nada más, mientras que más allá de sus fronteras la máxima fragmentación política (tantos eslovenos, macedonios y chechenos como sea posible) se busca sistemáticamente. De la movilización en torno a cuestiones sobre la "democracia" y los "derechos de los pueblos" se obtiene como resultado la anulación de la capacidad de los pueblos para hacer uso de la democracia y sus derechos, en cuyo nombre han sido manipulados. El elogio de la particularidad y la diferencia, la movilización ideológica en torno a objetivos étnicos o culturalistas, es el motor de un comunalismo impotente, y desplazan la lucha al campo de la limpieza étnica o el totalitarismo religioso.

En este marco, la lógica del "choque de civilizaciones" se convierte en posible, e incluso deseable. En mi opinión, así es como debe ser entendida la intervención de Huntington en esta materia. De la misma forma en la que en el pasado Huntington solía escribir textos que legitimaban las dictaduras del Tercer Mundo en el nombre del "desarrollo", en la actualidad ha escrito un texto con el que legitima las medidas implementadas para gestionar las crisis surgidas de la polarización de los conflictos debido a "incompatibilidades culturales". Esto no es más que una estrategia para imponer un escenario de conflicto que garantiza la victoria de "Occidente", como he señalado.

Los eventos parecen confirmar en el futuro inmediato, con la proliferación de los conflictos étnicos y religiosos, la eficacia de esta estrategia. ¿Pero prueban así la tesis del choque "natural" de culturas? Ya he expresado mis fuertes reservas al respecto. Las duras afirmaciones sobre la "particularidad" muy raramente son un producto espontáneo de los pueblos involucrados. Estas son casi siempre formuladas por las minorías en el poder, o que aspiran a conseguirlo. También es evidente que las clases dominantes que más se han debilitado debido a la evolución global del sistema [capitalista] son las que han recurrido más frecuentemente a estas estrategias culturalistas o étnicas. Este es el caso de los países de Europa del Este, que han sido afectados por un cataclismo de proporciones únicas. Pero es también el caso del mundo islámico y el África subsahariana, que también han sido eliminados de la lista de productores industriales competitivos $y$, por tanto, marginados en el sistema mundial. Estos nacionalismos negativos son, sin embargo, totalmente funcionales desde la perspectiva de la gestión de crisis del capitalismo. Ni la política exterior ni los servicios de Inteligencia de Estados Unidos, de los cuales Huntington es funcionario, han fallado 
al utilizar "diferencia" e "incompatibilidad cultural" contra los movimientos populares que han ofrecido resistencia (dentro del marco de los compromisos de la postguerra) a la expansión del capital. La asistencia que se prestó a figuras como, por ejemplo, Savimbi en Angola, Hekmatyar en Afganistán y Tudjman en Yugoslavia muestran que los ejemplos más aterradores de "conflicto cultural" en la actualidad pueden ser vistos, en cierta manera, menos que "naturales". Las culturas locales, en su particularidad y en sus relaciones con el sistema mundial y la cultura dominante del capitalismo, se consideran insuficientes en sí mismas para la deducción de una teoría general, como supondría el capitalismo. Las verdaderas claves para explicar las diferencias entre las regiones del mundo se encuentran fuera del campo de la cultura. No hay un "choque de culturas" sistemático: hay conflictos que son fundamentalmente de otra naturaleza, y en algunos se incluye el ámbito cultural. Por tanto, para poder definir una estrategia de lucha social, debemos empezar por el análisis de las contradicciones del capitalismo y las formas que adopta en el periodo histórico concreto que estamos viviendo. 


\section{RELACIONES INTERNACIONALES}

Revista académica cuatrimestral de publicación electrónica Grupo de Estudios de Relaciones Internacionales (GERI)

Universidad Autónoma de Madrid, España

https://revistas.uam.es/relacionesinternacionales

ISSN 1699 - 3950

f facebook.com/RelacionesInternacionales

3. twitter.com/RRInternacional

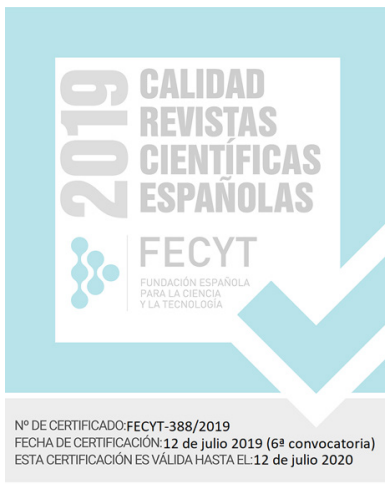

